\title{
HISTÒRIA I TRAMA: ELS CASOS CLÍNICS COM A RELATS ACADËMICS*
}

\author{
STORY AND PLOT: CLINICAL CASE REPORTS \\ AS ACADEMIC STORIES
}

\section{AdÉla Kot'ÁTKOVÁ \\ Institut Interuniversitari López Piñero, Universitat Jaume I \\ kotatkov@uji.es}

Resum: Els casos clínics constitueixen un gènere propi dels professionals sanitaris, que els redacten i publiquen amb propòsits didàctics i de recerca. A diferència d'altres textos científics, es basen en l'experiència clínica d'un o pocs pacients, per la qual cosa adopten un caràcter narratiu i una sèrie de característiques que ens condueixen a considerar-los com a relats acadèmics. En aquest article mirem d'esbrinar si aquesta consideració és apropiada. Revisem la teoria de la narració per identificar l'element clau que defineix el relat respecte d'altres textos narratius: la trama o intriga. Comprovem la presència d'aquest element en un corpus de casos clínics escrits en català, anglès i castellà publicats en revistes de l'àmbit de la salut mental.

Paraules clau: cas clínic, narració científica, relat acadèmic, trama, intriga.

Abstract: Clinical case reports constitute a genre specific of healthcare professionals, who write and publish them with educational and research purposes. Unlike other scientific texts, case reports are based on the clinical experience of one or a few patients. This is why they acquire a narrative character and a series of features that lead us to consider them as academic stories. In this article, we try to find out if this consideration is accurate. We review the narrative theory to identify the key element that defines stories with regard to other narrative texts: the plot or intrigue. We

$\left(^{*}\right)$ Aquest treball s'ha realitzat en el marc del projecte de recerca «La construcció discursiva del conflicte: territorialitat, imatge de la malaltia i identitats de gènere en la literatura i en la comunicació social» (FFI2OI785227-R), del Ministeri d'Economia, Indústria i Competitivitat, Govern d'Espanya. L'autora ha rebut finançament a través del programa Grisolía (GRISOLIA/20i6/055), de la Generalitat Valenciana. 
AdÉLA Kot'ÁTKOvá

Història $i$ trama: els casos clínics com a relats acadèmics

confirm the presence of this element in a corpus of written clinical case reports in Catalan, English and Spanish published in magazines from the mental health field.

Key words: clinical case report, scientific narrative, academic story, plot, intrigue.

\section{$\operatorname{cosectat}$}

\section{INTRODUCCIÓ}

Els humans sentim l'impuls de contar, tant als altres com a nosaltres mateixos, els esdeveniments que experimentem o creiem haver experimentat. Els records, les experiències vivencials, les emocions, no els emmagatzemem d'una manera separada, sinó que els entreteixim i els combinem per bastir un relat, la història de la nostra existència. Aquesta narració interna que construïm i reconstruïm contínuament és la base de nosaltres mateixos, ens ajuda a confegir i a mantenir el nostre jo, la nostra identitat. Podríem dir que, d'alguna manera, les nostres vides són en realitat un gran relat, un Quixot que no està exempt de contenir moltes altres petites històries.

Les malalties constitueixen fites rellevants en la vida de moltes persones i donen peu a capítols sencers en la narració de les seves existències. De vegades, el relat de la malaltia constitueix en si mateix la història de la vida de l'individu. A més de donar sentit a l'existència - $\mathrm{i}$ al patiment- dels individus, aquests relats adopten altres finalitats. Pensem ara en les persones que conten les seves malalties per socialitzar-se, per cercar l'empatia d'altres malalts o per conèixer altres opinions sobre diferents aspectes de la curació o de la prevenció. $\mathrm{O}$, si ho mirem des de l'altre costat, fixem-nos en els professionals sanitaris que cada dia es converteixen en espectadors d'històries que sovint ni la ficció literària no pot superar.

Entre els professionals sanitaris, narrar les experiències clíniques pot tenir diversos objectius: fer progressar la ciència, ensenyar els nous professionals, buscar ajuda dels col-legues del mateix àmbit o mostrar les experiències clíniques als companys de professió. Un gènere que respon a aquests propòsits comunicatius de les diverses branques de les ciències de la salut i en què es narren aquestes històries vitals és el cas clínic. Es tracta de textos altament especialitzats, redactats pels professionals, adreçats als seus col-legues i publicats en revistes acadèmiques.

Ens interessen els casos clínics, entre altres motius, perquè els considerem un pont entre la biomedicina científica i les humanitats (Kotátková 20I8), atès que es 
tracta d'estudis de base científica, però que no renuncien a una concepció personalitzada del pacient com a subjecte humà (Salvador 20I6). Concebem els casos clínics com a relats, com apunta el títol d'aquest article, en el qual mirarem de desenvolupar les raons teòriques que justifiquen aquesta adscripció i les contrastarem amb el nostre corpus de casos clínics.

Entenem el relat com una modalitat discursiva que està present més enllà de la literatura. La narració no existeix sols dins les cobertes dels llibres, sinó que impregna les nostres accions diàries, començant per allò que s'ha denominat la narració natural (Labov \& Waletzky 1967: 20-2I), a través de la qual recapitulem les experiències en l'ordre dels esdeveniments originals. Per això, lluny de ser una exclusivitat de la literatura, s'ha convertit en un objecte d'investigació en moltes altres disciplines, com ara la sociolingüística, l'antropologia social, la psicologia social... Així doncs, seguint Thornborrow i Coates (2005), tenim la convicció que el discurs narratiu s'entrellaça amb el teixit de la interacció social, ja sigui en les converses casuals, en els mitjans de comunicació, en les interaccions familiars o en els entorns mèdics.

En l'àmbit literari, òbviament, s'han desenvolupat incomptables teories i reflexions sobre el relat. Malgrat que l'interès per la narració es remunta a més d'un parell de mil.lennis, l'estudi sistemàtic es desenvolupa sobretot en el darrer mig segle, amb l'aparició d'una nova disciplina: la narratologia (Frank 20IO). Quan parem esment en alguns filòsofs i crítics literaris que avui dia es consideren pioners de la teoria narrativa, des d'Aristòtil fins a Vladimir Propp, o de Percy Lubbock a Wayne Booth, ens adonem que ells estudiaven els diferents gèneres literaris i no la narrativa com a tal. No és fins a l'estructuralisme francès, amb el seu objectiu de bastir models científics per a les disciplines humanes i socials, i els seus exponents Roland Barthes i Claude Bremond, que es comença a abordar «as a semiotic phenomenon that transcends disciplines and media» (Ryan 2005). Per a Barthes (1970: 9):

el relato puede ser soportado por el lenguaje articulado, oral o escrito, por la imagen, fija o móvil, por el gesto y por la combinación ordenada de todas estas sustancias; está presente en el mito, la leyenda, la fábula, el cuento, la novela, la epopeya, la historia, la tragedia, el drama, la comedia, la pantomima, el cuadro pintado (piénsese en la Santa Úrsula de Carpaccio), el vitral, el cine, las tiras cómicas, las noticias policiales, la conversación. Además, en estas formas casi infinitas, el relato está presente en todos los tiempos, en todos los lugares, en todas las sociedades; el relato comienza con la historia misma de la humanidad; no hay ni ha habido jamás en parte alguna un pueblo sin relatos; todas las clases, todos los grupos humanos, tienen sus relatos y muy a menudo estos relatos son saboreados en común por hombres de cultura diversa e incluso opuesta: el relato se burla de la buena y de la mala literatura: internacional, transhistórico, transcultural, el relato está allí, como la vida. 
AdÉLA Kot'ÁTKová

Història $i$ trama: els casos clínics com a relats acadèmics

Així doncs, el relat es pot entendre com un concepte molt ampli que abasta nombrosos gèneres i situacions comunicatives. Aquesta amplitud mateixa, juntament amb la multiplicitat d'enfocaments teòrics, pot comportar imprecisions i variacions terminològiques. ${ }^{1}$ En català i castellà, sovint s'usa indistintament narració o relat per referir-nos al resultat de l'acció de narrar, és a dir, a una successió d'esdeveniments que es produeixen al llarg d'un temps determinat i que, habitualment, causen una transformació de la situació inicial. Tanmateix, com veurem en el segon apartat d'aquest article, és més útil concebre el relat com un tipus específic de narració, caracteritzat per la presència d'una trama o intriga.

En el tercer apartat, tractarem de mostrar el caràcter de relat acadèmic dels casos clínics, mitjançant els exemples representatius seleccionats entre un corpus de cent quinze casos clínics recents (publicats a partir de l'any 2000) en tres llengües (català, castellà i anglès), provinents de dotze revistes, butlletins i portals en línia especialitzats, indexats o avalats per entitats professionals de prestigi de diversos camps relacionats amb les afeccions mentals, principalment de la neurologia, la psiquiatria i la psicologia, però també d'àrees més especialitzades com l'atenció precoç, l'adolescència o la síndrome de Down (Kotátková 20I9). Els autors són principalment neuròlegs, psiquiatres i psicòlegs, encara que també hi ha altres professionals de la salut que aborden casos clínics en aquest àmbit, com ara infermers o logopedes:

- Revista Mèdica Internacional sobre la Sindrome de Down

- Neurologia Catalana. Butlleti de la Societat Catalana de Neurologia

- Desenvolupa: la Revista d'Atenció Precoç

- Revista de Neurología

- Revista Cientifica de la Sociedad Española de Enfermería Neurológica

- Adolescere. Revista de Formación Continuada de la Sociedad Española de Medicina de la Adolescencia

- Revista Electrónica de PortalesMedicos.com

- Czech and Slovak Neurology and Neurosurgery

- Case Reports in Neurological Medicine

- Case Reports in Psychiatry

- Frontiers in Psychology

- Case Reports in Neurology

I. En l'ús dels termes més bàsics per a l'anàlisi del nostre corpus seguim, sobretot, Routledge Encyclopedia of Narrative Theory (Herman, Jahn \& Ryan 2005) i Françoise Revaz (I997 i 2009). 


\section{LA HISTÒRIA I LA TRAMA EN ELS TEXTOS NARRATIUS}

La major part de les teories narratives estan d'acord amb el fet que hi ha almenys dos nivells en un text narratiu: allò que passa i la manera com es conta. Per a aquests dos nivells (el què i el com) podem trobar noms diferents segons cada tradició teòrica. L'estructuralisme ha estat un dels corrents més influents en aquest àmbit i en la seva terminologia "the what of the narrative is called story, the how is called discourse» (Lethbridge \& Mildorf 2004). Aquesta teoria, per tant, distingeix entre la història, com una seqüència d'accions o esdeveniments independents de la seva presentació discursiva, i el discurs, com a representació narrativa particular d'aquests esdeveniments (Genette 1980).

Els formalistes russos anomenaven aquesta distinció amb els termes fabula i sujet, tot i que els conceptes no són del tot coincidents amb els genettians d'història i discurs (vegeu-ne més en Pimentel 1995). En el món anglosaxó, es van traduir els termes del rus per story (fabula) i plot (sujet). Aquesta tria, però, potser no va ser la més encertada (García Landa 1998), perquè aquests dos termes tradicionals ja existien en anglès i no reflecteixen el mateix tipus de relació que els russos, però al capdavall és la que ha fet fortuna i trobem, per exemple, en l'estudi clàssic Aspects of Novel, de Forster (1985: 27-28):

\footnotetext{
It [story] is the lowest and simplest of literary organisms. Yet it is the highest factor common to all the very complicated organisms known as novels. [...] A story, by the way, is not the same as a plot. It may form the basis of one, but the plot is an organism of a higher type.
}

Forster (1985: 86) és també l'autor de l'exemple que més repercussió ha tingut en les obres posteriors, amb el qual diferencia aquests dos conceptes. Hi remarca que la història (story) són els successos ordenats seguint una seqüència temporal: «The king died and then the queen died». En canvi, en la trama (plot) també hi ha una seqüència temporal de successos, però l'èmfasi es posa en la causalitat «The king died and then the queen died of grief».

Així doncs, entendrem la història com una seqüència d'esdeveniments en ordre cronològic, en la qual alguna cosa canvia de l'estat A a l'estat B. La trama, en canvi, es refereix a la manera i les etapes en què es configuren i resolen els conflictes cabdals. Així, la trama (plot) designa "the ways in which the events and characters' actions in a story are arranged and how this arrangement in turn facilitates identification of their motivations and consequences» (Kukkonen 20I4: Plot). Aquests patrons causals i temporals poden ser determinats pel discurs narratiu mateix o inferits pels lectors. Per tant, segons Kukkonen (20I4), la trama es troba entre els fets d'una narració al

Caplletra 70 (Primavera, 2021), p. 81-101 
AdÉLA Kot'ÁTKová

Història i trama: els casos clínics com a relats acadèmics

nivell de la història i la seva presentació al nivell del discurs. No està subjecta a cap mode particular d'expressió narrativa i es pot observar en una gran quantitat de mitjans i gèneres.

La trama de la tradició anglosaxona ens recorda el concepte d'intriga que, segons Françoise Revaz, caracteritza els relats respecte de les altres narracions. L'autora (I997 i 2009) es planteja si la presència d'accions en un text implica un veritable criteri de categorització, és a dir, si qualsevol text d'acció és una narració. L'autora analitza textos tan diversos com el reportatge esportiu, la recepta, la publicitat, el conte, la faula o la novel.la. Es basa teòricament en la retòrica antiga (com ara Aristòtil o Quintilià), la clàssica (Du Marsais o Marmontel), la narratologia contemporània (Bremond o Genette) i la filosofia de l'acció de Paul Ricœur.

Seguint Revaz, diferenciem els estats i els processos. Els estats són descripcions sense desenvolupament temporal, estàtiques. Els processos, per la seva banda, inclouen dues subcategories: les accions i els esdeveniments. Els esdeveniments són fenòmens que es produeixen en la naturalesa sota l'efecte d'una causa. Es podrien considerar una categoria intermèdia entre l'acció i l'estat, i la major diferència que els separa de les accions és la manca d'agentivitat humana. Com a exemple, podem pensar en una descripció de la pluja sense la presència d'agents humans. L'acció és un dels conceptes que ens permet categoritzar els casos clínics com a narracions. Es tracta d'una conducta humana —o d'una entitat antropomorfitzada—, amb una raó per a actuar —un motiu—, amb una intenció. Aquesta és la principal diferència amb l'esdeveniment: la presència o l'absència d'agent humà.

Aquesta dicotomia entre esdeveniment i acció també es pot constatar en el fet que l'esdeveniment es pot explicar mitjançant lleis, mentre que l'acció humana només es pot entendre, és a dir, sols la podem interpretar. La comprensió de les accions no és tan transparent, però, com podria semblar a primera vista, perquè sempre és el resultat d'un procés d'interpretació bastant complex. Així doncs, hem de tenir en compte dos elements (Revaz 2009: 45-46): (a) tota conducta humana no ha de ser necessàriament intencional, ja que hi ha graus de motivació i de responsabilitat de l'agent humà; (b) l'acció humana no és pas la producció d'un actor solitari, sinó que s'adscriu a un context cultural, històric i social regit per normes.

Revaz manlleva moltes idees del filòsof Paul Ricœur (1986: I69), qui intenta defugir una categorització estricta entre l'acció i l'esdeveniment, però reconeix que:

ce n'est pas dans le même jeu de langage que l'on parle d'événements se produisant dans la nature, ou d'actions faites par des hommes. Car pour parler d'événements, on entre dans un jeu de langage comportant des notions telles que cause, loi, fait, explication etc. Il ne faut pas mêler les jeux de langage, mais les séparer. C'est donc dans un autre jeu de langage et dans un 
autre réseau conceptuel que l'on parlera de l'action humaine. Car, si on a commencé à parler en termes d'action, on continuera à parler en termes de projets, d'intentions, de motifs, de raisons d'agir, d'agents, etc.

Així, podem veure la diferència en els exemples citats: Bayard meurt 'Bayard mor' és clarament un esdeveniment, mentre que tuer Bayard 'matar Bayard' és una acció. En el primer cas, no hi ha agentivitat humana perquè — en principi- pensaríem en una mort natural. Seria, per tant, un esdeveniment. El segon exemple, en canvi, implica la presència i l'actuació d'un ésser animat, amb una raó per a actuar d'aquesta manera. Així doncs, per saber si un procés és una acció o un esdeveniment, podem fixar-nos si al darrere hi ha un motiu (una raó per a actuar) o una causa (de l'esdeveniment).

Arribats en aquest punt, cal constatar l'associació de l'acció i el relat (récit) com a fruit de l'oposició literària entre la narració i la descripció, la qual estableix el relat com a lloc textual de les representacions de les accions, mentre que la descripció seria el lloc de representació dels estats (Genette 1969: 59):

Il faut observer enfin que toutes les différences qui séparent description et narration sont des différences de contenu, qui n’ont pas à proprement parler d'existence sémiologique: la narration s'attache à des actions ou des événements considérés comme purs procès, et par là même elle met l'accent sur l'aspect temporel et dramatique du récit; la description au contraire, parce qu'elle s'attarde sur des objets et des êtres considérés dans leur simultanéité, et qu'elle envisage les procès eux-mêmes comme des spectacles, semble suspendre le cours du temps et contribue à étaler le récit dans l'espace.

En la taula següent (I), podem observar que la dicotomia entre estats i processos (que inclouen les accions i els esdeveniments) es pot traslladar també a la dicotomia entre descripció i narració. Així, Revaz (2009) formalitza aquesta oposició clàssica.

\begin{tabular}{|l|l|l|}
\hline Représentation & ÉTATS & ACTIONS OU ÉVÉNEMENTS \\
\hline Temporalité & SIMULTANÉITÉ & CONSÉCUTION \\
\hline Catégorie textuelle & DESCRIPTION & NARRATION \\
\hline
\end{tabular}

Taula I: La dicotomia entre la descripció i la narració (Revaz 2009: I03)

Així doncs, juntament amb l'esdeveniment, l'acció seria un tret característic dels textos narratius, inclosos els relats. Tanmateix, cal recordar que no tots els textos que presenten accions es poden considerar relats. D'altres com els informes, els horòscops, les notícies necrològiques o les receptes poden contenir representacions d'accions, sense que els puguem considerar relats (Revaz 1997: 8). A més, cal recordar que la narrativitat es pot entendre d'una manera no absoluta, sinó gradual: és a dir,

Caplletra 70 (Primavera, 2021), p. 81-101 
AdÉLA Kot'ÁTKová

Història i trama: els casos clínics com a relats acadèmics

que determinats textos es poden considerar més narratius que altres (Prince 20I2). De fet, Revaz defensa l'existència de categories intermèdies entre la descripció i el relat, tal com podem veure en la taula 2.

\begin{tabular}{|l|l|l|l|l|l|}
\hline Représentation & \multicolumn{1}{|c|}{ ÉTATS } & \multicolumn{3}{c|}{ ACTIONS } \\
\hline Temporalité & SIMULTANÉITÉ & \multicolumn{2}{c|}{ CONSÉCUTION } \\
\hline Causalité & \multicolumn{3}{|c|}{-} & \multicolumn{2}{|c|}{ ACTION « UNE » } \\
\hline Composition & \multicolumn{2}{|c|}{ TABULARITÉ } & $\begin{array}{l}\text { MISE EN IN- } \\
\text { TRIGUE }\end{array}$ \\
\hline Mise en texte/discours & DESCRIPTION & TABLEAU & CHRONIQUE & $\begin{array}{l}\text { RELATION } \\
\text { RECETTE }\end{array}$ & RÉCIT \\
\hline Action langagière & décrire & dépeindre & rapporter & relater & raconter \\
\hline
\end{tabular}

Taula 2: Revaz (1997: 238). La negreta correspon a l'original de l'autora

L'autora proposa distingir entre quatre categories de textos d'acció: la categoria del tableau 'quadre' (representació d'accions simultànies); la categoria de chronique 'crònica' (representació d'accions successives, no vinculades per relacions causals); la categoria de recette 'recepta' o relation 'relació' (representacions d'accions successives que formen una unitat); i, finalment, la categoria de récit 'relat' (representació d'accions successives que formen una unitat $i$, a més, presenten una estructura d'intriga). Les quatre categories corresponen a la narrativitat, però cadascuna s'associa a una manera específica d'introduir el text (o el discurs) que caracteritza una activitat lingüística particular: depeindre 'pintar', rapporter 'informar', relater 'relatar', raconter 'contar' (Revaz I997: 238).

Cal parar atenció a la terminologia usada per l'autora i a la seva traducció al català: la relació es relata, però no equival al relat. El nostre 'relat' correspon al récit, el qual, com hem vist i a diferència de la relació (o de la recepta), requereix intriga. Per a Revaz, si l’acció defineix la narració, la intriga delimita el relat.

Així és també en la tradició anglosaxona, en la qual Elinor Ochs (2000) remarca que és precisament la trama la que distingeix un relat respecte d'una llista d'esdeveniments. Quan un narrador crea una trama, estructura les accions i els esdeveniments en un esquema amb un determinat sentit. Al capdavall, podem concebre la trama com una teoria dels fets, entesa com una explicació dels esdeveniments contats des d'un punt de vista particular. Veient-ho així, la trama podria ser un tret distintiu del relat literari, però també del relat científic (Ochs 2000: 283):

En este sentido, los relatos son afines a las narraciones científicas. Si bien estas últimas quitan todo énfasis a los agentes y motivos, comparten con las narraciones de relatos la propiedad 
de contar algo que está fuera de lo usual: un enigma, una discrepancia, una rareza, un desafío, un fenómeno que perturba el equilibrio. Además, tanto las narraciones científicas como las personales tratan de esclarecer un problema al colocarlo dentro de una secuencia de sucesos y circunstancias según las leyes de causa y efecto.

\section{ELS CASOS CLÍNICS COM A RELATS ACADÈMICS}

Atesos els fonaments teòrics que hem exposat, podem concebre els casos clínics com narracions científiques, perquè presenten una successió cronològica d'esdeveniments i d'accions. Però, a més, en podem considerar la condició de relats, ja que els autors no sempre presenten els processos en un ordre cronològic estricte, sinó que els organitzen en una trama o intriga, a fi de palesar millor la seva visió sobre la causalitat de la malaltia (Hydén 2005: 296):

\footnotetext{
In case presentations, narratives are used in order to describe the circumstances that resulted in a patient coming to the attention of the medical system. They also describe the nature of the patient's problem or disease, what has been done, and what is planned. These narratives subordinate the chronological chain of events of the patient's life to a plot of relevant medical goals and events.
}

A l'hora d'escriure ficció, un dels recursos per a captar l'atenció del lector és jugar amb la forma i l'ordre en què se li van presentant aquests esdeveniments. Es pot contar la història seguint un ordre temporal, des de les informacions més antigues fins a les més recents, però en la ficció també és possible i sovint convenient alterar aquesta línia temporal per construir una trama més atractiva, més intrigant. Tanmateix, les històries que es reflecteixen en els casos clínics no són ficcions. En aquest apartat examinem si els casos clínics consisteixen només en un cúmul de fets ordenats cronològicament (story) o si hi trobem una intriga o trama (plot) que estructura un relat. Així, estudiem de quina manera s'organitza la trama en relació amb la línia temporal —la història - dels casos clínics publicats en les revistes especialitzades del nostre corpus.

Podem concebre la línia temporal com la vida real del pacient, de la qual només coneixerem les parts i els detalls que ens en proporcionarà el professional sanitari en el seu text. La història que s'explica en un cas clínic seria, doncs, el procés lineal de la malaltia del pacient. Aquesta malaltia/història comença en algun moment —uns primers símptomes o un esdeveniment desencadenant, per exemple- $\mathrm{i}$ té un punt final que pot ser molt divers: pot consistir en el guariment definitiu, en una cronificació o, en últim extrem, en la mort. Entre aquests dos punts pot haver-hi una sèrie d'esdeveniments diversos, com ara altres símptomes, visites als metges, proves clíniques... 
AdÉLA Kot'ÁTKová

Història i trama: els casos clínics com a relats acadèmics

Ara bé, quan cerquem aquesta línia temporal de la història en els casos clínics, veiem que els professionals de la salut reben els pacients en diferents punts de la malaltia - i en poques ocasions des del seu inici. En la majoria de casos, els pacients no van a la consulta en el moment exacte en què comença la malaltia, ja que encara potser ni n'han aparegut els primers símptomes o, inicialment, no els han donat gaire importància. En el cas de la salut mental és encara més complex que no pas si parlem, per exemple, de braços o cames trencades. Les afeccions mentals tenen també el seu punt de partença — on comença la història — però és complicat d'establir i sovint l'ha d'esbrinar el professional sanitari, tant si l'origen del problema és físic —com veiem en els casos clínics de neurologia_ com quan és psicològic. Decidir on s’inicia la malaltia implica també definir-la, establir què n'és un símptoma i què no ho és. Freqüentment, aquesta tasca només es pot fer de manera retrospectiva, perquè és quan es desenvolupa la malaltia que hom sap que està malalt.

En certa mesura, els casos clínics narren no com han passat els fets, sinó com s'ha arribat a definir i decidir quin és el problema. Així doncs, normalment comencen amb un contacte entre el professional i el pacient, en un moment que no és, des del punt de vista cronològic, l'inici de la història. Freqüentment, el text continua amb l'anamnesi, una mena de flashback clinic, una presentació del pacient amb un repàs — breu en la majoria de casos — de l'historial mèdic i d'altres qüestions pertinents que podrien tenir relació amb les dolències del malalt, com il.lustren els exemples I-4:

(I) Se trata de una paciente de I8 años de edad que acude al Servicio de Urgencias hospitalario de su zona por dolor abdominal epigástrico de tipo cólico de dos semanas de evolución; asociado a náuseas y sensación diatérmica, sin otro síntoma asociado. Refiere cuadro similar un año atrás, en contexto de situación de estrés. [...] Reconsulta al día siguiente, en el mismo servicio, por persistencia del dolor que ha ido en aumento en las últimas horas, acompañado de sensación nauseosa. [...] Acude por primera vez a su pediatra de atención primaria ig días tras la consulta al centro hospitalario.

(González, Hidalgo \& Casanova 20I6: 6I) ${ }^{2}$

(2) Home de 6I anys que ingresa a l'abril de 2005 per impotència funcional d'extremitats d'instauració progressiva de nou mesos d'evolució. Al juny de 2004, s'inicien rampes a extremitats inferiors de predomini nocturn. Dos mesos després, s'afegeixen parestèsies i

2. Transcrivim totes les citacions del corpus sense intervenció lingüística, és a dir, sense corregir-ne les errades que puguin contenir. 
hipoestèsia d'inici simètric a mans i peus i debilitat global de les quatre extremitats amb un cert predomini distal.

(Martínez Piñeiro 2009: 8)

(3) A thirty-one-year old married male was brought to the psychiatry service due to a suicide attempt after an indecent sexual behavior. He was perplexed, suspicious, and seemed talking with hallucinatory figure.

The patient was brought up in a conservative family and studied in a residential religious institution. His teachers and senior students abused him physically and sexually at the age of eight. Within a few months, this boy started abusing new students sexually and developed sexual relation with multiple boys. At the age of $\mathrm{I} 6$ years, his most intimate sexual partner left the hostel. He became suspicious that other students and teachers conspired against him and forced the partner to leave the hostel. Afterwards his suspiciousness spread to every aspect of his life.

(Rashid Soron 2016: 2)

(4) Varón de 69 años, ingresado por alteración gradual del estado de conciencia que progresó hasta el coma en alrededor de 24 horas. El cuadro comenzó cinco años antes con pérdida parcial de la visión con predominio en el ojo izquierdo. El paciente fue diagnosticado de neuritis óptica y tratado sin éxito con corticoides e inmunosupresores. Posteriormente, presentó depresión, insomnio y anhedonia, y seis meses antes de su ingreso desarrolló gradualmente inestabilidad postural, rigidez, marcha parkinsoniana, temblor de intención en las extremidades superiores, bradicinesia, episodios de desorientación, amnesia, alucinaciones visuales complejas y deterioro cognitivo, que empeoraron hasta llevarlo al estado de postración. Previamente a nuestra valoración, el paciente había recibido levodopa/carbidopa y memantina, sin obtener respuesta terapéutica. En el momento del ingreso, el sujeto se encontraba en estupor, no emitía lenguaje, sus pupilas eran simétricas y reactivas, y los reflejos oculares de versión cefálica estaban intactos.

(Mejía, Piedra \& Merchán-Del Hierro 20I7: 214)

Són força habituals, doncs, els casos clínics que comencen in medias res, quan alguna cosa s'agreuja i això fa que el malalt vagi a l'hospital o a la consulta (exemples I-4). Però, òbviament, també trobem casos que comencen ab ovo, des del principi o quasi des del principi de la malaltia o dels primers símptomes (exemples 5-6). Aquests fragments segueixen impecablement una successió cronològica de la malaltia. Tanmateix, encara que el primer text hagi començat amb els canvis de comportament del pacient als I3 anys, o que el segon iniciï amb el dolor experimentat en l'any 1999, són uns problemes i uns símptomes molt posteriors els que els han conduït a l'atenció dels professionals que n'estan contant les històries. És per això que el més habitual és que els casos clínics comencin per la presentació del pacient i la raó per la qual ha 
AdÉLA Kot'ÁTKová

Història i trama: els casos clínics com a relats acadèmics

anat a la consulta o ha estat hospitalitzat i que, a continuació, se'n faci la revisió de l'historial en ordre cronològic.

(5) It is about a 5o-year-old male patient, native of Cajamarca [...]

Since the age of $\mathrm{I} 3$ the patient has presented behavioral changes, with marked isolation due to fearing other people and poor school performance so he repeated third year of high school. [...]

At age 45 the patient was afraid to leave home, as he thought he would be killed. [...]

At age 49, the patient began to live alone in Cajamarca. He did not care about personal hygiene nor basic needs; he began giving away his belongings. [...]

Three months before the admission to our unit, the patient moved to Lima with his son and started working in the cleaning area of a school. [...]

Twenty days before admission to our unit, the patient refused to eat; he said the food was rotten as he was. [...]

Seven days before admission to our unit, the patient mentioned that he was already dead, his stomach did not work, his liver was decomposed, his brain was paralyzed, and his face lacked blood. [...]

Four days before admission to our unit, the patient's relatives took him to a psychiatric hospital due to persistence of symptoms. He was again diagnosed with schizophrenia and admission was indicated.

The patient remained hospitalized for three days. [...] Since he did not show any improvement, his family decided to bring him to the emergency room of our hospital, before being admitted to the service of General Psychiatry.

The patient was significantly improved after two weeks of treatment.

(Huarcaya-Victoria, Ledesma-Gastañadui \& Huete-Cordova 2016: 2)

(6) Se trata de una paciente de 52 años de edad, que en el año 1999 comienza con dolores a nivel de articulaciones, sequedad de piel y mucosas acudiendo a consulta de inmunología [...] En el año 2002 recurre sintomatología siendo remitida al Centro Nacional de Reumatología con cuadros de dolores articulares y lesiones purpuropetequiales de miembros inferiores [...] Ingresa en abril 2orr al Hospital Camilo Cienfuegos por cefalea [...] En marzo/20II recurre cuadro neurológico con excitación motora, desorientación, intranquilidad ingresa nuevamente en UCIM [...] Es traída el I3 del mismo mes con toma de conciencia y depresión respiratoria falleciendo a pocas horas de su ingreso.

(Calderón Chongo \& Barreto Castro 2013) ${ }^{3}$

Tanmateix, també hi ha casos clínics que quasi no remeten als antecedents de la malaltia. En fan el seguiment a partir de la primera consulta i analitzen tots els

3. Text sense paginació. 
esdeveniments posteriors. En aquests fragments es presenta un cas clínic (exemple 7) que es desenvolupa arran de l'ingrés a urgències (excepte una petita referència als fets anteriors a l'entrada a l'hospital: "de horas de evolución») d'un pacient amb mutisme acinètic després d'una cirurgia de fossa posterior per una fístula arteriovenosa, complicada amb hemorràgia diencefalica i hidrocefalia, que va respondre espectacularment al tractament amb bromocriptina:

(7) Varón de 43 años, que ingresó con clínica de cefalea y hemiparesia izquierda de predominio crural de horas de evolución. En urgencias presentó una disminución progresiva del nivel de consciencia hasta presentar Glasgow de 6-7 ( $\left.\mathrm{OIV}_{\mathrm{I}} \mathrm{M}_{4}\right)$, con desaturación y posibles crisis tonicoclónicas generalizadas. [...]

Durante su ingreso en la unidad de cuidados intensivos se realizó una arteriografía, donde se objetivó una fístula arteriovenosa dural de tipo III de la clasificación de Cognard (Fig. 2). $[\ldots]$

Una vez en planta de hospitalización, el paciente sufrió un tromboembolismo pulmonar como complicación más destacada, que precisó ingreso de nuevo en la unidad de cuidados intensivos, tratamiento con heparina y trombectomía, pero que finalmente se resolvió sin más complicaciones añadidas.

Durante todo este período, la exploración física del paciente se mantuvo estable, y destacó un síndrome mesencefálico [...]

Una vez estabilizada su situación clínica, tras la retirada de la cánula de traqueotomía y su traslado a la planta de hospitalización, se comenzó el tratamiento rehabilitador [...] El paciente fue reevaluado un mes después y se objetivó una clara mejoría de su componente de abulia [...]

El paciente fue dado de alta con traslado a un hospital de daño cerebral para continuar con su rehabilitación. Se reevaluó dos meses después en consultas externas y se observó una clara progresión en su mejoría neurológica global.

(Arévalo-Sáenz, Pedrosa-Sánchez \& García de Sola 2017: 70-74)

Així, en el cas que no hi hagi historial mèdic o que aquest no contingui res de rellevant en relació amb el problema pel qual el pacient es troba a la consulta o a l'hospital, la història comença des de la trobada amb el metge i es desenvolupa a partir de les proves i les analítiques que se li fan. Aquesta variant sense anamnesi es pot trobar també en els casos clínics dels pacients que arriben a l'hospital sense poder comunicar-se amb el personal sanitari (sigui perquè estan, per exemple, en coma, per alguna deficiència mental o per manca d'una llengua compartida).

Cal dir que alguns casos clínics no comencen ni pel principi de la malaltia ni per cap punt intermedi, sinó directament pel final: per la mort del pacient i la voluntat del professional d'esbrinar el motiu del traspàs. Són els casos de la medicina forense. 
AdÉLA Kot'ÁTKová

Història $i$ trama: els casos clínics com a relats acadèmics

En els altres casos clínics, si el pacient es mor, el lector sovint no se n'assabenta fins al darrer paràgraf de la presentació del cas clínic (imatge I).

nopathy (Fig. 3). He underwent endoscopic evaluation for his anemia and weight loss that revealed benign polyps in the stomach, duodenum, descending colon, and sigmoid colon. Further workup with fine needle aspiration of the supraclavicular lymph node revealed a high-grade, diffuse large B-cell malignant lymphoma. Immunohistological staining showed CD20(+), CD79s(+), CD43(+), and BCL-6(+). The patient developed resistant hypercalcemia and tumor lysis syndrome. The family opted for comfort measures and hospice care, hence further workup including onconeural antibodies were not pursued. He continued to deteriorate and subsequently expired.

\section{Discussion}

Evaluation of patients presenting with cranial nerve palsies is challenging as the etiology is very extensive. A patient may present with single or multiple cranial nerve palsies. Mul-

Imatge I: Kumar et alii (2017: 56)

Veiem, doncs, que els casos clínics presenten solucions diverses pel que fa a la representació de les informacions anteriors a la consulta, tant les proporcionades per l'historial mèdic com també pel pacient o pel seu entorn. Aquestes darreres s'obtenen mitjançant l'entrevista mèdica, un sistema d'intercanvi de veu socialment estructurat, organitzat jeràrquicament en fases (Drass I98I) i en el qual la interacció entre pacients i metges és asimètrica, ja que aquests darrers controlen els temes que s'hi tracten, fan preguntes i sovint desvien les inquietuds dels pacients (Anspach 1988). Generalment, els malalts, quan conten la raó per la qual han anat a la consulta mèdica, tenen diverses possibilitats d'organitzar temporalment la informació: poden començar per algun dels fets més recents que els hi han portat o pels primers problemes o símptomes que han tingut i que pensen que estan relacionats amb el problema actual. També poden anar saltant en la línia temporal a mesura que recorden els possibles símptomes. Així, doncs, els pacients tampoc no acostumen a seguir la línia temporal, malgrat que ho intentin. Sovint el metge pregunta "Quan va començar a fer-li mal...?» i el pacient intenta recordar la primera molèstia o el primer símptoma i es posa a narrar la seva història. Alguns pacients, com que s'esperen aquesta pregunta, ja es preparen a casa o a la sala d'espera la seva versió dels fets. Normalment, però, no aconsegueixen contar-ho tot cronològicament, perquè el metge també els interromp freqüentment amb altres preguntes que poden portar els malalts tant a un passat encara més antic de la seva línia temporal narrativa com, de sobte, a alguna qüestió més recent. 
A part de les informacions obtingudes de l'entrevista amb el pacient o els familiars, també hi ha detalls del passat mèdic del pacient que el professional sanitari ha d'investigar, com si fos un detectiu, per poder resoldre el cas, ja que el pacient sovint no pot proporcionar-li tota la informació. El professional de la salut agafa les dades proporcionades pel pacient, en selecciona les rellevants per al cas clínic i hi afegeix els resultats d'altres procediments mèdics, com ara les analítiques que es van efectuar a partir de la consulta, per detectar quina malaltia tenia el pacient. És a dir, el metge ha de repassar o descobrir els fets rellevants que no controla, anteriors a la consulta. Aquests fets els pot esbrinar mitjançant les proves posteriors a la consulta i la informació que li proporcionen el pacient o els familiars.

A diferència del pacient, qui generalment explica els fets de manera oral i improvisada, el professional sanitari té el temps i la possibilitat de reorganitzar la informació, atès que prepara un discurs en forma escrita, sovint amb una distància temporal, a partir dels seus apunts, dels resultats clínics, etc. A més de la possibilitat de seleccionar la informació pertinent i de canviar l'ordre dels fets, el professional recrea el discurs del malalt i l'eleva a un registre més adequat per integrar-lo dins del seu discurs.

Amb tot això, constatem que els casos clínics rarament s'organitzen com un simple cúmul de fets ordenats cronològicament, ja que hi ha una selecció dels esdeveniments i de les dades que es mencionen. També es tria quin espai se'ls dona, en quin moment i com estan relacionats entre si. Encara que bona part de la informació estigui narrada més o menys cronològicament, els autors avancen o posposen determinades informacions i amb això donen més o menys importància a determinats fets i creen així el que podem considerar una tensió narrativa o intriga. D'aquesta manera, els casos clínics s'assemblen a una història literària, com ara un conte clàssic en el qual els fets se solen presentar d'una manera més o menys cronològica, però també contenen algunes digressions. En els cas dels contes, n'hi ha molts tipus diferents: des dels més clàssics fins als que intenten trencar les regles narratives. En els casos clínics, el que trobem són textos de caire més narratiu — sobretot si tracten afeccions psiquiàtriques o psíquiques - i els que es presenten sobretot com una sèrie de resultats de proves biomèdiques —un estil freqüent en neurologia.

Així doncs, els casos clínics poden seguir una mena de narració natural, és a dir, conten una història seguint, a grans trets, l'ordre cronològic — com esperaríem i consideraríem lògic en un informe científic. Però això no s'esdevé sempre, ni de bon tros, de manera escrupolosa. Particularment els casos clínics d'algunes especialitats, com ara la psicologia, poden tenir un caire molt marcadament narratiu i assemblar-se encara més a un conte literari, ja que narrar l'entorn i la vida del pacient és més rellevant per al cas que en altres especialitats. Els autors, per tant, agafen els esdeveniments que en 
AdÉLA Kot'ÁTKová

Història i trama: els casos clínics com a relats acadèmics

la vida real passen en una successió lògica (i cronològica) i els reordenen d'acord amb els seus interessos discursius. En el fragment següent del cas clínic «Adolescente con anorexia nerviosa», podem veure que, en l'anamnesi de la mare de la pacient, no se segueix l'ordre cronològic de cap manera:

(8) La madre apunta que de pequeña era una niña «algo rellenita». Han notado que Itziar, que siempre ha sido una niña alegre, feliz y dócil, está más irritable, enfadándose con frecuencia y sin motivo, con tendencia a encerrarse en su cuarto. Nunca ha sido una niña muy comunicativa. Ha empeorado el rendimiento escolar, ya que era «una chica de sobresaliente». Tiene una amiga con "problemas en la alimentación».

(Casas Rivero, Guerrero Alzola \& Salmerón Ruiz 2015: 74)

No hi tenim primerament una presentació de com era l'adolescent de petita i després com van començar a aparèixer problemes amb l'anorèxia, sinó que les informacions passades i les actuals s'hi barregen. Els autors opten per una estructura més dinàmica al'hora de relacionar els fets entre si, sense seguir totalment l'ordre cronològic.

Per descomptat, els autors dels casos clínics no es poden permetre jugar amb la intriga al nivell que ho fan els autors dels textos literaris. Tanmateix, com hem vist, tampoc no podem dir que els casos clínics siguin simples acumulacions d'esdeveniments ordenats cronològicament. Des del nostre punt de vista, els casos clínics manifesten una trama i els hem de considerar, doncs, relats. De fet, salvant totes les distàncies d'intencionalitat literària, el cas clínic mostra grans paral-lelismes amb el procediment de la novel.la negra. El desenvolupament prototípic de la novel.la negra sovint comença per un detectiu privat que rep la visita d'un client que li encomana un cas. El client li facilita unes informacions seleccionades sobre la història en qüestió (anamnesi) i posteriorment, al llarg de la novel.la, el detectiu haurà d'investigar el que ha passat realment, amb resultats sovint contradictoris als que pretenia el client. D’una manera similar, el cas clínic s'inicia sovint amb una consulta en la qual el pacient explica al professional el que sap —o creu saber o vol comunicar — sobre la història que pretén desentranyar — la malaltia_, i el professional sanitari és el detectiu que haurà de desenvolupar les proves necessàries i revisar els fets del passat per treure l'entrellat d'aquesta història.

(9) The patient is a 28 -year-old man... He localized his pain to the right lower quadrant, complained of right lower quadrant pain with palpation of the left lower quadrant (Rovsing's sign), and indicated his pain was reproducible with extension of the right hip (psoas sign).

[...] the patient mentioned that he had been struggling with sadness and suicidality since his pregnant fiancé had recently been killed in an automobile accident. The emergency 
physicians felt the pretest probability for acute appendicitis was extremely high and asked the psychiatry consult-liaison team to «evaluate him quickly before he goes to surgery.» Ultimately, the imaging was negative for acute appendicitis, surgery was cancelled, and his disposition from the emergency department was left to psychiatry. [...]

We obtained information from a local emergency community outreach agency which indicated that the patient had presented with the chief complaint of suicidality to multiple emergency departments in the city resulting in two previous inpatient psychiatric stays over the past year. We obtained records from his most recent inpatient psychiatric hospitalization about six months ago, where he presented with depression related to his girlfriend's putative recent breast cancer diagnosis. He was discharged on an antidepressant, a mood stabilizer, and oxycodone for chronic back pain.

When gently confronted with these inconsistencies, the patient appeared unperturbed and easily provided further elaborate details to explain them. However when further pressed, he stated he believed he needed a "dramatic» reason for his depression and suicidality to receive help and asked, «Can I just be depressed and suicidal?» He appeared perplexed as to why we attempted to clarify his previous statements or their relevance for his care. Despite this, he continued to state that he felt very depressed and would not be able to maintain his safety in the community.

(Thom, Teslyar \& Friedman 20I7: I-2)

Com hem vist en aquests fragments del cas clínic «Pseudologia Fantastica in the Emergency Department: A Case Report and Review of the Literature», les qüestions relacionades amb la salut mental s'ofereixen encara més a l'existència d'històries en les quals el personal sanitari ha de tenir en compte les paraules del malalt, però també contrastar-les amb altres dades disponibles. És en aquest àmbit on trobem els casos més peculiars i curiosos que facilment podrien convertir-se en històries literàries.

\section{CONCLUSIÓ}

En aquest article partim d'una concepció de la narrativa i del relat que va més enllà de l'àmbit literari i que està present en la comunicació quotidiana, en allò que, seguint Labov i Waletzky denominem narració natural (1967: 20-2I). Aquest discurs narratiu, d'acord amb Thornborrow i Coates (2005), està present en nombroses interaccions socials, des de les més familiars i casuals a les mèdiques i científiques. En aquest marc, hem revisat diversos conceptes de la teoria del relat per aplicar-los al gènere mèdic dels casos clínics, en defensa d'una concepció d'aquest textos com a relats acadèmics. En concret, ens interessa la dicotomia d'història i trama, en el sentit emprat per Forster (1985), en què la història es refereix als esdeveniments en estricta

Caplletra 70 (Primavera, 2021), p. 81-101 
AdÉLA Kot'ÁTKová

Història i trama: els casos clínics com a relats acadèmics

successió temporal, mentre que la trama expressa la causalitat. Especialment rellevant resulta també el concepte d'intriga, anàleg al de trama i que, d'acord amb Revaz (I997) individualitza els relats respecte de la resta de les narracions.

Hem estudiat l'organització temporal dels fets en un corpus de casos clínics en català, anglès i castellà, com també la presència de la trama o intriga, com un element clau per a poder-los qualificar de relats. Hem pogut constatar que els casos clínics rarament s'organitzen com un mer cúmul d'accions i esdeveniments ordenats cronològicament, ja que hi podem detectar una selecció i una disposició intencionals dels fets. Malgrat que una bona part de les informacions se sol narrar seguint l'ordre cronològic — com esperaríem i consideraríem lògic en un informe científic-, els professionals sanitaris també empren el recurs d'avançar o posposar determinades dades. D'aquesta manera, assignen a alguns fets més o menys importància que a d'altres i així també poden crear una espècie de tensió narrativa o intriga.

Els fets que han seguit una successió cronològica en la vida real del pacient passen a ser narrats per aquest —o els seus familiars — en un ordre alterat — normalment des dels fets que més els preocupen— i són agafats pel professional sanitari, el qual els selecciona, els combina amb les dades de l'historial mèdic i les proves clíniques, i els reordena d'acord amb els seus interessos discursius. A partir de la història que aconsegueix descabdellar, el professional confegeix la trama del cas clínic i, per tant, un relat. Podem, doncs, concebre els casos clínics com relats acadèmics, és a dir, com un gènere narratiu no literari, altament especialitzat, que se situa entre els gèneres científics.

AdÉla Kot' ÁTKOvÁ Institut Interuniversitari López Piñero / Universitat Jaume I kotatkov@uji.es ORCID: 0000-0003-2395-7473

\section{REFERÈNCIES BIBLIOGRÀFIQUES}

Anspach, R. R. (1988) «Notes on the Sociology of Medical Discourse: The Language of Case Presentation", Journal of Health and Social Behavior, 29, pp. 357-375.

Barthes, R. (1970) «Introducción al análisis estructural de los relatos», dins Roland Barthes etal. (ed.), Análisis estructuraldel relato, Buenos Aires, Editorial Tiempo Contemporáneo, pp. 9-44.

Drass, K. A. (I98I) The Social Organization of Mid-Level Provider-Patient Encounters (tesi doctoral), Indiana University. 
Forster, E. M. (1985) Aspects of the Novel, Harmondsworth, Penguin Books.

Frank, A. W. (2010) Letting Stories Breathe: A Socio-Narratology, Chicago/Londres, University of Chicago Press.

García Landa, J. Á. (1998) Acción, Relato, Discurso: Estructura de la ficción narrativa, Salamanca, Ediciones Universidad de Salamanca. <https://ssrn.com/ abstract $=2480262>$ [Consulta: 29 de maig de 2020]

Genette, G. (1969) Figures II, París, Seuil.

- (1980) Narrative Discourse. An Essay in Method, Oxford, Blackwell.

Herman, D., M. Jahn i M. Ryan (eds.) (2005) Routledge Encyclopedia of Narrative Theory, Abingdon/Nova York, Routledge.

HydÉn, L. (2005) «Medicine and Narrative», dins D. Herman, M. Jahn i M. Ryan (eds.), Routledge Encyclopedia of Narrative Theory, Abingdon/Nova York, Routledge.

Kơ̌ÁTKová, A. (20I8) «Un puente entre las ciencias médicas y las humanidades: aproximación a los discursos de la salud», Studia Iberica et Americana (SIBA), Monograph 5: 37-54.

- (2019) El relat en l'àmbitsanitari: els casos clínics sobre afeccions mentals (tesi doctoral), Castelló de la Plana, Universitat Jaume I.

Kunkonen, K. (20I4) «Plot», dins Peter Hühn et al. (eds), The Living Handbook of Narratology, Hamburg, Hamburg University Press. <https://www.lhn.unihamburg.de/> [Consulta: 29 de maig de 2020]

Labov, W. i J. Waletzky (1967) «Narrative Analysis: Oral Versions of Personal Experience», dins J. HeLm (ed.), AES Essays on the Verbal and Visual Arts. Proceedings of the I966 Annual Spring Meeting. American Ethnological Society, Seattle, American Ethnological Society, pp. I2-44.

Lethbridge, S. i J. Mildorf (2004) Basics of English Studies: An Introductory Course for Students of Literary Studies in English, Universitats de Tübingen, Stuttgart i Freiburg. <http://www2.anglistik.uni-freiburg.de/intranet/englishbasics/Discourseor.htm - storydisc> [Consulta: 29 de maig de 2020]

Ochs, E. (2000) «Narrativa», dins Teun van Dijk (ed.), El discurso como estructura y como proceso, Buenos Aires, Gedisa, pp. 27I-304.

Pimentel Luz, A. (1995) «Teoría narrativa», dins Esther Cohen (ed.), Aproximaciones. Lecturas del texto, Ciutat de Mèxic, Universidad Nacional Autónoma de México, pp. 257-287.

Prince, G. (20I2) "Récit minimal et narrativité», dins S. Bedrane, F. Revaz i M. VIEGNes (eds.), Le récit minimal: Du minime au minimalisme. Littérature, arts, médias, París, Presses Sorbonne Nouvelle, pp. 23-32.

Caplletra 70 (Primavera, 2021), p. 81-101 
AdÉLA Kot'ÁTKová

Història i trama: els casos clínics com a relats acadèmics

Revaz, F. (1997) Les textes d'action, París, Klincksieck.

- (2009) Introduction à la narratologie: Action et narration, Louvain-la-Neuve, De Boeck-Duculot.

Ricceur, P. (I986) Du texte à l'action. Essais d'herméneutique, volum 2, París, Seuil.

Ryan, M. (2005) «Narrative», dins D. Herman, M. Jahn i M. Ryan (eds.), Routledge Encyclopedia of Narrative Theory, Abingdon/Nova York, Routledge.

Salvador, V. (2016) «The Clinical Case Report as a Discourse Genre in the Context of Professional Training», dins P. Ordóñez-López i N. Edo-Marzá (eds.), Medical Discourse in Professional, Academic and Popular Settings, Bristol, Multilingual Matters, pp. 3I-54.

Thornborrow, J. i J. CoAtes (2005) «The Sociolinguistics of Narrative: Identity, Performance, Culture», dins J. Thornborrow i J. Coates (eds.), The Sociolinguistics of Narrative, Amsterdam, John Benjamins, pp. I-I6.

\section{CORPUS CITAT}

Arévalo-Sáenz, A., M. Pedrosa-Sánchez i R. García de Sola (20I7) «Bromocriptina: ¿podría ser la cura para el mutismo acinético posquirúrgico?», Revista de Neurología, 64(2), pp. 70-74. <https://doi.org/I0.33588/rn.6402.2016430> [Consulta: 29 de maig de 2020]

Calderón Chongo, Á. A. i R. Barreto Castro (2013) «Psicosis lúpica. Presentación de un caso", Revista Electrónica PortalesMedicos.com. <https://www.revistaportalesmedicos.com/revista-medica/psicosis-lupica-caso-clinico/> [Consulta: 29 de maig de 2020]

Casas Rivero, J., F. Guerrero Alzola i M. A. Salmerón Ruiz (20i5) «Adolescente con anorexia nerviosa", Adolescere. Revista de Formación Continuada de la Sociedad Española de Medicina de la Adolescencia, III(I), pp. 74-8I. <https:// www.adolescenciasema.org/adolescente-con-anorexia-nerviosa-j-casas-riverof-guerrero-alzola-m-a-salmeron-ruiz-caso-clinico-adolescere-20I5-iii-I-74-8I/> [Consulta: 29 de maig de 2020]

González Gómez, B., M.I. Hidalgo Vicario i C. Casanova Garcia (20i6) «Dolor abdominal persistente», Adolescere. Revista de Formación Continuada de la Sociedad Española de Medicina de la Adolescencia, IV(3), pp. 6I-66. <https://www. adolescenciasema.org/caso-clinico-dolor-abdominal-persistente-b-gonzalezgomez-m-i-hidalgo-vicario-c-casanova-garcia-adolescere-20I6-iv-3-6I-67/> [Consulta: 29 de maig de 2020] 
Huarcaya-Victoria, J., M. Ledesma-Gastañadui i M. Huete-Cordova (20i6) "Cotard's Syndrome in a Patient with Schizophrenia: Case Report and Review of the Literature», Case Reports in Psychiatry. <http://dx.doi.org/I0.II55/2016/6968409> [Consulta: 29 de maig de 2020]

Kumar, K., R. Ahmed, B. Bajantri, A. Singh, H. Abbas, E. Dejesus, R. Raheel Khan, M. Niazi i S. Chilimuri (20I7) «Tumors Presenting as Multiple Cranial Nerve Palsies", Case Reports in Neurology, 9, pp. 54-6r. <https://doi. org/IO.II59/000456538> [Consulta: 29 de maig de 2020]

Martínez Piñeiro, A. (2009) «Impotència funcional d'extremitats d'instauració llargament progressiva», Neurologia Catalana, 8, pp. 8-9.

Mejía, P., L. M. Piedra i X. Merchán-Del Hierro (20I7) «Demencia rápidamente progresiva y parkinsonismo asociados a múltiples fístulas arteriovenosas durales», Revista de Neurología, 64(5), pp. 214-218. <https://doi.org/I0.33588/ rn.6405.2016387> [Consulta: 29 de maig de 2020]

Rashid Soron, T. (2016) "A Case Report on Management of Father Daughter Incest with Schizophrenia", Case Reports in Psychiatry. <http://dx.doi. org/IO.II55/2016/40IOI87> [Consulta: 29 de maig de 2020]

Thom, R., P. Teslyar i R. Friedman (20I7) «Pseudologia Fantastica in the Emergency Department: A Case Report and Review of the Literature», Case Reports in Psychiatry. <https://doi.org/IO.II55/20I7/8961256> [Consulta: 29 de maig de 2020] 